\title{
Lazer e urbanização no Brasil: notas de uma história recente (décadas de 1950/1970)
}

Cleber Augusto Gonçalves*

Victor Andrade de Melo**

\begin{abstract}
Resumo: Este artigo objetiva discutir a relação entre a aceleração do processo de urbanização do Brasil, observável a partir dos anos 1950, e de forma ainda mais intensa ao longo dos anos 1960 e 1970, e os novos arranjos do fenômeno lazer em nossa sociedade. $O$ intuito é analisar as possíveis correspondências entre um certo aspecto da cultura (o lazer) e as formas assumidas ou idealizadas para um território. Para alcançar esse objetivo, além de uma revisão da bibliografia, utiliza-se como fonte principal um periódico semanal de grande circulação, penetrabilidade e influência, lançado nos anos 1960: a revista Veja.

Palavras-chave: Atividade de lazer. Urbanização. Natureza. Cidades.
\end{abstract}

\section{INTRODUÇÃO}

Entre os pesquisadores que vêm se dedicando a investigar o fenômeno social "lazer", há uma corrente, em certo sentido majoritária, que o identifica como uma das decorrências da série de mudanças que marca a modernidade; para ser mais preciso, observadas desde o final do século XVIII. Nesse caso, entende-se que emerge de um conjunto de circunstâncias interdependentes geradas pela industrialização, pela ascensão da burguesia ao poder, pela nova organização do tempo de trabalho (em função do desenvolvimento do modelo de produção fabril), pelo novo modo de circulação de mercadorias e pela nova configuração das cidades (MELO; PERES, 2005), assunto que interessa mais diretamente neste estudo.

\footnotetext{
* Doutorando em Educação Física (Unicamp). Mestre em História Comparada UFRJ. Especialista em Educação Física escolar (UFF). Graduado em Educação Física. Pesquisador do Anima. Brasil. E-mail: cag.dias@bol.com.br

** Coordenador do "Sport": Laboratório de História do Esporte e do Lazer. Professor do Programa de Pós-Graduação em História Comparada/IFCS/UFRJ e da Escola de Educação Física e Desportos/UFRJ. Rio de Janeiro, RJ, Brasil. E-mail: victor.a.melo@uol.com.br
} 


\section{Artifor Originais}

Cléber Gonçalves, Victor de Melo

Tendo em vista que a relação entre o desenvolvimento das cidades e o lazer parece ser uma constante no decorrer da história (CORBIN, 2001), este artigo tem por objetivo discutir a relação entre a aceleração do processo de urbanização ao Brasil, observável a partir dos anos 1950, e de forma ainda mais intensa ao longo dos anos 1960 e 1970, e os novos arranjos do fenômeno lazer na sociedade. $\mathrm{O}$ intuito é analisar as possíveis correspondências entre um certo aspecto da cultura (as práticas de lazer e seus sentidos e significados) e as formas assumidas ou idealizadas para um território.

Para alcance do objetivo, além de uma revisão da bibliografia, utiliza-se como fonte principal uma revista semanal de grande circulação, penetrabilidade e influência, lançada nos anos 1960: a Veja.É importante ressaltar que esse periódico, atualmente cercado por polêmicas, em função do enfoque de suas matérias, possuía na época da análise, um perfil diferenciado. Mesmo que deva-se considerar que nenhuma publicação é isenta, falando sempre para um público específico idealizado, naquele momento, para uma classe média em crescimento e consolidação, a Veja adotava uma linha editorial marcada pela busca da veracidade, imparcialidade e independência. Por tal perfil, por seu alcance nacional e pela natureza das reportagens publicadas, pareceu, portanto, adequada aos intuitos deste estudo.

Concentrou-se a análise fundamentalmente em dois aspectos. $\mathrm{O}$ primeiro diz respeito às relações entre a reorganização espacial e à fisionomia de algumas das maiores cidades brasileiras à época (notadamente o Rio de Janeiro, que vivia um momento de transição, com a transferência da capital federal para Brasília) e a incorporação de novos estilos urbanos de vida, caracterizados inclusive pela ampliação da possibilidade de consumo de novos produtos.

Argumenta-se que tais estilos se materializaram também no desenvolvimento e na consolidação de hábitos de lazer, tais como o costume de viajar, de ir às compras e de fazer esportes e atividades físicas, entre as quais pode-se identificar a popularização daquelas vivenciadas em contato com a natureza, uma forma de buscar compensação para os problemas do "cinzento mundo urbano". À medida que algumas cidades iam crescendo e as condições de vida passavam a

Movimento, Porto Alegre, v. 15, n. 03, p. 249-271, julho/setembro de 2009. 
ser avaliadas como caóticas, desumanas, opressoras ou maléficas, um conjunto de novas práticas foi sendo apresentado, de maneira crescente, como bálsamo para os problemas decorrentes do inchaço urbano.

O segundo aspecto, articulado ao anterior, diz respeito ao crescimento de iniciativas do mercado e de preocupações governamentais relacionadas ao uso do tempo livre das populações metropolitanas. As mudanças na configuração das cidades deram origem a um sentimento coletivo, que foi interpretado tanto pelos empreendimentos comerciais quanto pelos órgãos governamentais, que passaram mais denotadamente a propor e implementar intervenções diversas.

O intuito é, portanto, observar uma possível dupla articulação entre lazer e cidade, identificando como se influenciaram reciprocamente, tecendo uma imbricada e complexa trama social envolvendo o território e o espaço.

\section{INDUSTRIALIZAÇÃO, URBANIZAÇÃO, CONSUMO E LAZER}

Segundo Eric Hobsbawm (1998), às vésperas do início da Segunda Guerra Mundial, a população de todos os países do mundo com exceção da Inglaterra e da Bélgica - era composta por pelo menos um quarto de trabalhadores rurais. Mesmo em alguns países bastante urbanizados, como a França e a Suécia, os que viviam no campo correspondiam a, pelo menos, $35 \%$ do total.

No período que se segue ao término do referido conflito bélico, esse quadro mudaria rapidamente. Na América Latina, a percentagem de decréscimo da população camponesa foi da ordem de $50 \%$, num período de apenas vinte anos. Se, em 1940, apenas quatro cidades latino-americanas possuíam população superior a um milhão de habitantes (Buenos Aires, Cidade do México, Rio de Janeiro e São Paulo) e cinco ultrapassavam 500.000 (Lima, Rosário, Havana, Montevidéu e Santiago do Chile), nas décadas seguintes, o número de municípios superpovoados aumentaria exponencialmente em todo o continente (ROMERO, 2004).

Movimento, Porto Alegre, v. 15, n. 03, p. 249-271, julho/setembro de 2009. 


\section{Antigos Originais Cléber Gonçalves, Victor de Melo}

No Brasil, essa dinâmica tem início na década de 1950, momento de grande mudança na economia nacional. Se o processo de industrialização já estava bem definido desde os anos 1930, e no final da década de 1940 o país já fosse autossuficiente na produção de bens manufaturados não duráveis (alimentos e bebidas, tecidos e confecções) (FURTADO, 1983), nos anos iniciais dos anos 1950 "a indústria já podia ser considerada o "carro chefe' do desenvolvimento" (MOREIRA, 2003, p. 178).

Esse processo é potencializado no âmbito do governo Juscelino Kubitschek (1956-1961), notadamente com o incremento da produção de bens de consumo duráveis e destinados a um mercado interno. ${ }^{1}$ O aço, produzido pela Companhia Siderúrgica Nacional, pela Acesita, pela Cosipa e pela Usiminas, e os derivados do petróleo (a gasolina, o asfalto, o plástico, entre outros), produzidos pela Petrobrás e suas subsidiárias, eram utilizados para a fabricação de determinados bens de consumo que até então só eram acessíveis pela via da importação. A indústria automobilística é um dos exemplos mais emblemáticos dessa nova dinâmica. No fim dos anos 1950, onze montadoras já estavam instaladas no Brasil. ${ }^{2}$

A partir de meados dos anos 1960, as políticas implementadas pelos governos militares de exceção contribuíram para a sedimentação de um modelo de organização econômica que privilegiava os capitais internacionais (PRADO; EARP, 2003). Instalar determinadas indústrias (como a elétrica, a química, a farmacêutica ou mesmo a automobilística) exigia uma considerável quantidade de equipamentos sofisticados e o domínio de uma tecnologia complexa. Por conta disso, era necessário um grande volume de investimento inicial, mais acessível às multinacionais ou às empresas estatais.

\footnotetext{
${ }^{1}$ Se, em 1949 , os setores alimentícios e têxteis representavam cerca $50 \%$ de toda a produção industrial nacional, dez anos depois, em 1959, somavam apenas $36 \%$. Cederam espaço para outros segmentos tecnologicamente mais avançados que, no mesmo período, cresceram a uma taxa média anual de 15,2\%, dobrando a intensidade de produção manufatureira (FURTADO, 1983). ${ }^{2}$ A Fábrica Nacional de Motores (caminhões pesados e carros), a Ford e a General Motors (caminhões leves e médios), a Internacional Harvester (caminhões médios), a Mercedez-Benz (caminhão médio, caminhão pesado e ônibus), a Scania Vabis (caminhão pesado), a Simca (automóvel), a Toyota (jipe), a Vemag (caminhonete, automóvel e jipe), a Volkswagen (caminhonete e automóvel), a Willis (jipe, caminhonete, e os automóveis Aero-Willis e Dauphine-Renault).

Movimento, Porto Alegre, v. 15, n. 03, p. 249-271, julho/setembro de 2009.
} 
No meio rural, observa-se a forte tecnologização da produção agrícola, exigência das novas condições de comercialização do mercado internacional. É nesse momento que grandes empresas do ramo alimentício, como a Perdigão e a Sadia, ampliam seus complexos agroindustriais.

A mecanização da agricultura reduziu as possibilidades de trabalho no campo, empurrando um enorme contingente de pessoas para a cidade. Ao mesmo tempo, nas metrópoles, as chances e oportunidades de emprego apresentavam-se mais atraentes, graças à implementação das novas indústrias, ao crescimento do setor de construção civil, à ampliação das administrações e dos serviços públicos e à expansão do comércio e do setor de serviços em geral. Como bem afirma Romero (2004, p. 360):

\begin{abstract}
A grande cidade abrigava uma intensa atividade terciária, com muita luz, vários serviços de índole diversa, inúmeros comércios grandes e pequenos, muita gente de boa posição que podia precisar de criados ou dos variados serviços próprios da vida urbana; a atração era ainda maior se a cidade havia começado a dar o salto para a industrialização [...] Ali o imigrante poderia encontrar "trabalho urbano": nos serviços, no comercio ou na indústria.
\end{abstract}

Assim, ao longo da década de 1950, 8 milhões de pessoas migraram para as cidades brasileiras, cerca de $24 \%$ da população rural do país naquele momento; nos anos 1960, 14 milhões de brasileiros migraram; nos anos 1970, o número de migrações ultrapassou os 17 milhões. Em apenas três décadas, portanto, 39 milhões de pessoas deixaram o campo (MELLO; NOVAIS, 1998).

Nos anos 1970, a população da região metropolitana de São Paulo ultrapassou o número de 10 milhões de habitantes: quintuplicou, num período de apenas 20 anos. No Grande Rio de Janeiro, já havia mais de 8 milhões de habitantes: 4 vezes mais do que em 1950. A população residente em Belo Horizonte e redondezas superou a marca de 2 milhões. Processo semelhante pode ser observado em Porto Alegre, Recife e Salvador (MELLO; NOVAIS, 1998).

Esse processo deixa marcas visíveis nas cidades. No Rio de Janeiro, por exemplo, isso desencadeou uma série de mudanças que

Movimento, Porto Alegre, v. 15, n. 03, p. 249-271, julho/setembro de 2009. 


\title{
254 Artigos Origimais Cléber Gonçalves, Victor de Melo
}

davam sequência e acentuavam um processo que já estava em desenvolvimento desde a transição dos séculos XIX e XX, no âmbito das reformas urbanas conduzidas por Pereira Passos (1902-1906). ${ }^{3}$

A construção de parques industriais demandou a reconfiguração da estrutura urbana, no sentido de dotá-la de condições de atender às novas necessidades de produção. Alguns bairros cariocas devem seu primeiro grande fluxo de ocupação à instalação de fábricas, algo inclusive relacionado ao desenvolvimento de novas possibilidades de transporte:

\begin{abstract}
Nos anos 40 e 50 mais de 220 indústrias de médio e grande porte fixaram-se ao longo dos eixos ferroviários. Maria da Graça desenvolveu-se com a General Electric; Bonsucesso, com a Cerâmica Klabin; Del Castilho, com a Companhia Nacional de Tecidos Nova América; Benfica com a Gillete do Brasil; Irajá, com o Cimento Branco; Honório Gurgel, com diversas indústrias químicas; Bangu, com a Companhia Progresso Industria; Inhomirim com a Fábrica Estrela; Xerém com a Fábrica Nacional de Motores etc [...] A combinação do subsídio crescente nas tarifas ferroviárias com a inauguração da avenida Brasil em 1940, favoreceu o crescimento dos municípios da Baixada. Porém o movimento mais significativo foi o deslocamento das indústrias (LESSA, 2000, p. 252).
\end{abstract}

Para além das condições propriamente materiais, há também um deslocamento da "estrutura de necessidades": novos padrões de organização econômica trazem consigo novos desejos e aspirações; uma nova visão de mundo e escala de valores. O oferecimento de bens de consumo duráveis para o mercado interno altera sensivelmente as expectativas de uma considerável parcela da população. Deve-se ainda ter em conta que isso dialoga como o fato de, na nova configuração das cidades, haver novas e melhor remuneradas profissões.

\footnotetext{
${ }^{3}$ Segundo Abreu (2006), desde as ações Passos, buscava-se ajustar a malha urbana carioca às necessidades dos novos padrões econômicos: incentivava-se a implementação do capitalismo simultaneamente à superação da antiga fisionomia da cidade. Da mesma forma, a elaboração do "Plano de Remodelação, Extensão e Embelezamento", assinado pelo francês Alfred Agache, no âmbito da gestão do prefeito Antonio Prado Junior (1926-1930), também pretendia responder à "existência de um setor industrial, que se tornara realidade a partir da Primeira Guerra Mundial" (REZENDE, 2002, p. 260).
}

Movimento, Porto Alegre, v. 15, n. 03, p. 249-271, julho/setembro de 2009. 
Estar na cidade significava a possibilidade de acessar mais facilmente os novos produtos da indústria nacional. Adquiri-los significava tomar posse de algo que encarnava o arquétipo do moderno. As cidades se tornavam os lugares onde o "mais moderno" se realizava. Os padrões de sociabilidade passam a ser marcados pela valorização dos produtos da "civilização tecnológica", cujo símbolo maior é o automóvel.

As cidades precisam adaptar-se à crescente presença de carros. Casas e edifícios têm que levar em conta o "novo membro da família". No início dos anos 1960, são alteradas as leis de edificação, no sentido de proibir a construção de prédios sem garagem. Avenidas são construídas avidamente, passando por cima da velha cidade e celebrando, prática e simbolicamente, a "definitiva chegada do progresso".

Sob os auspícios dessa nova maquinaria urbana, surgem e/ou se consolidam determinadas práticas de lazer. Por exemplo, ter um automóvel, ou mesmo poder recorrer aos ônibus, em um país que investe maciçamente no sistema rodoviário, estimula o hábito de viajar. Ao longo da década de 1960, essa possibilidade se tornou cada vez mais acessível, como informa a revista Veja de 17 de dezembro de 1969, p. 74: "Viajar pelo Brasil deixava de ser um privilégio [...] Em 69, 4 milhões de brasileiros viajavam".

Nos anos 1960, é lançado o hoje tradicional Guia 4 Rodas, começa a crescer o número de agências de turismo e a modificar-se sensivelmente a estrutura hoteleira do país, inclusive com o lançamento do Motel Clube do Brasil, cujo título permitia o acesso a uma boa rede de hospedagem a preços compatíveis.

O aumento do estímulo e da possibilidade de viajar é mais uma expressão da difusão de serviços e produtos que até então eram vistos como um luxo pouco acessível e que se tornavam, paulatinamente, um padrão de conforto desejado por um espectro mais amplo da população. Isso era algo observável também no cenário internacional:

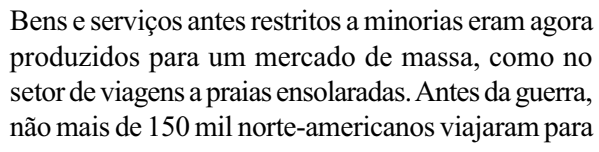

Movimento, Porto Alegre, v. 15, n. 03, p. 249-271, julho/setembro de 2009. 


\begin{abstract}
a América Central ou um Caribe em um ano, mas entre 1950 e 1970 esse número cresceu de 300 mil para 7 milhões. Os números para a Europa foram, sem surpresa, ainda mais espetaculares. A Espanha, que praticamente não tinha turismo de massa até a década de 1950, recebia mais de 44 milhões de estrangeiros por ano em fins da década de 80 , um número ligeiramente superado apenas pelos 45 milhões da Itália (HOBSBAWM, 1998, p. 259).
\end{abstract}

As mudanças no sistema produtivo também foram acompanhadas de alterações na forma de comercialização: surgia o supermercado e, fundamentalmente, o shopping center. No Rio de Janeiro, o supermercado Disco destaca-se ao suplantar em volume de venda os antigos armazéns e açougues. Em São Paulo, o primeiro shopping do país, o Iguatemi, inaugurado em 1966, "transformou-se num verdadeiro templo do consumo e de lazer" (MELLO; NOVAIS, 1998, p. 566).

Afirmava-se, na revista Veja de 30 de janeiro de 1974, p. 40: "Definitivamente, a era dos shopping centers chegou ao Brasil. Verdadeiras cidades, com vida e leis próprias, começam a invadir as principais cidades brasileiras." Não surpreende, assim, que hodiernamente a ida aos shoppings seja um dos principais hábitos de lazer. Uma análise sobre o uso do tempo livre na região metropolitana de São Paulo, realizada pelo Centro de Estudos da Metrópole (2005), confirma essa tendência, resultado que pode ser estendido a outras grandes cidades brasileiras.

Em conjunto, essas evidências reforçam um entendimento de que estávamos diante de um novo cenário estrutural de influência político-econômica-cultural, que tinha os Estados Unidos como principal parâmetro:

Ao estourar a Segunda Guerra Mundial, o predomínio da cultura francesa, em todas as suas facetas, era marcante entre nós. Paris, romanticamente visualizada como em terna belle époque, era o centro mundial das letras, das artes, dos prazeres. A catástrofe militar a isolar-nos da Europa e a ligar-nos mais de perto aos Estados Unidos, assinalou sob a premência das circunstâncias, mudanças de rumos (CUNHA, 1968, p. 9).

Movimento, Porto Alegre, v. 15, n. 03, p. 249-271, julho/setembro de 2009. 
Essa dinâmica vai decodificando um deslocamento no processo de formação de identidades, com a forte valorização da posse e aquisição de bens materiais. No dizer de Néstor García Canclini (2005, p. 26), "[...] com a Europa aprendemos a ser cidadãos, com os Estados Unidos aprendemos a ser consumidores".

Se é verdade que a ideia de lazer e de consumo como forma de status e distinção é algo que se pode observar desde os primórdios da constituição da sociedade moderna (MELO; PERES, 2005), também é fato que se pode perceber mudanças no interior dessa compreensão ao longo dos anos. Uma delas é a crescente preponderância do "consumo conspícuo" em detrimento do "ócio conspícuo" como método mais eficaz para o exibicionismo, conforme explica Veblen (1987, p. 42):

\begin{abstract}
Os meios de comunicação e a mobilidade da população expõem o indivíduo à observação de muitas pessoas que não têm outros meios de julgar da sua boa reputação exceto mediante a exibição de bens [...] o único meio prático de impressionar esses observadores não simpatizantes da nossa vida cotidiana é a demonstração ininterrupta da nossa capacidade de pagar. Na comunidade moderna há também uma freqüência mais assídua de grandes reuniões de gente que desconhece o nosso modo de vida em lugares tais como a igreja, o teatro, o salão de baile, os hotéis, os parques, as lojas e semelhantes. A fim de impressionar esses observadores, e a fim de manter a satisfação própria em face da observação deles, a marca da força pecuniária da pessoa deve ser gravada em caracteres que mesmo correndo se possa ler.
\end{abstract}

Certamente podemos perceber algo semelhante na sociedade brasileira: em larga medida, o crescimento e a consolidação de novas formas de usufruir o tempo livre também estavam ligados ao desejo de demonstrar padrões de consumo distintivos.

Enfim, no cenário do Brasil das décadas de 1950-1970, notadamente nas maiores cidades, cresce um mercado no qual vemos delineadas novas práticas de lazer. Proliferam-se serviços como restaurantes, agências de viagens, danceterias, hotéis e academias de ginástica, entre outras. Sintomaticamente, indicando os novos

Movimento, Porto Alegre, v. 15, n. 03, p. 249-271, julho/setembro de 2009. 


\section{Artigor Orifimais Cléber Gonçalves, Victor de Melo}

sentidos e representações do ato de se divertir, vemos publicado na edição da Veja de 12 de dezembro de 1973, p. 82: "As férias modernas não são mais um privilégio de uma reduzida casta, especialmente para um povo que atravessa auspiciosa fase de crescimento em todos os seus fronts estatísticos" .

\section{LAZER E URBANIZAÇÃO: AS PREOCUPAÇÕES COM O CORPO E A VALORIZAÇÃO DA NATUREZA}

O surgimento e/ou consolidação de hábitos de lazer também estão diretamente relacionados aos "efeitos mentais" desencadeados pela nova organização das metrópoles. Na medida em que as taxas demográficas vão aumentando, a euforia inicial vai dando lugar à condenação desse ambiente urbanizado. As cidades passam a ser retratadas como "um pesadelo de multidões", dotadas de um "cotidiano cercado de tormentos". A vida urbana passa a ser avaliada como insalubre, infectada, comprometida pelo ar sujo e poluído. Nos anos 1970, chega a surgir a expressão "urbicídio", uma espécie de eufemismo para falar do patológico e prejudicial entorno.

Não era raro, assim, retratar-se o fim de semana como um tempo em que prevalecia um "impulso irresistível, inquietante até, de se entregar às oportunidades de fugir da cidade", um momento em que prevalecia "a aventura da fuga": "Sociólogos, psicólogos e urbanistas tentavam explicar as razões que levam uma multidão de pessoas a deixarem a cidade como quem se livra de um pesado fardo" (VEJA, 15 de novembro de 1978, p. 55).

Nesse contexto, vemos crescer as preocupações com os "cuidados com o corpo e com a alma". Aulas de meditação e outros tratamentos espirituais passam a encontrar boa acolhida entre as classes médias brasileiras. Do mesmo modo, popularizava-se ainda mais o exercício físico como forma de ocupação do tempo livre. A necessidade e o desejo de "desempenar os corpos" passam a ser mais comumente notados. Afirma-se, na Veja de 2 de dezembro de 1974, p. 50:

A ginástica, até hoje usada como um método complementar para regimes de emagrecimento, começa a

Movimento, Porto Alegre, v. 15, n. 03, p. 249-271, julho/setembro de 2009. 
ser usada indistintamente por gordos e magros, principalmente como uma forma de movimentarem seus corpos, empenados no círculo vicioso criado pela vida das grandes cidades

O suor entrava na moda. Segundo matéria publicada na Veja de 3 de outubro de 1979, p. 51, estima-se que o número de "institutos e centros de ginástica" tenha saltado de pouco mais de uma dezena para mais de 50, num período de cerca de quatro anos: "A explosão do esporte e do exercício vai se tornando também um fenômeno de massa [...] Centenas de milhares de brasileiros, em suma, descobrem que um dos seus maiores interesses, quando não é o maior, é o próprio corpo"

Cresce também a valorização da ideia de natureza. O sol, o mar e a montanha passam a ser cada vez mais adorados. Esse "culto" era também perceptível no surgimento de novos modismos, como o da jardinagem como hobby, da valorização de restaurantes de comida natural/macrobiótica e da popularização de certas práticas realizadas em contato com o ambiente natural.

Em 1966, é fundado, no Rio de Janeiro, o Camping Clube do Brasil, com o objetivo de criar uma rede nacional de espaços adequados para acampamento. Quatro anos depois, já havia mais de 120 clubes de camping por todo o país. O campismo se consolidava como costume de lazer. Estes locais eram assim definidos na revista Veja de 8 de janeiro de 1969, p. 49:

[...] um espaço verde adequado para a recreação, o repouso e o turismo, com todos os recursos de conforto doméstico [...] um lugar onde adultos e crianças ficam livres da sufocante falta de espaço dos apartamentos, da irritante paisagem de concreto, da pressa neurotizante, do barulho, do ar poluído.

Para atender o rápido crescimento de uma nova demanda urbana, ciosa por reencontrar a vida campestre em suas "férias no campo", cresce também o número de hotéis fazendas (VEJA, 19 de janeiro de 1977).

Nesse cenário, entende-se porque a Empresa Brasileira de Turismo cria, no final dos anos 1970, "um núcleo pioneiro de lazer

Movimento, Porto Alegre, v. 15, n. 03, p. 249-271, julho/setembro de 2009. 
planejado que visa impedir a degradação do ambiente selvagem pela leva crescente de turistas, cada vez mais atraídos pela vida em contato com a natureza" (VEJA, 26 de outubro de 1977, p. 63).

Os esportes desenvolvidos em contato com a natureza se popularizam. O surfe, que, em menos de uma década, se disseminou entre jovens de classe média da Zona Sul do Rio de Janeiro, é um exemplo claro nesse sentido. Quando da realização do V Festival de Surf, realizado em Saquarema, um adepto, explicando a presença de grande público, declarara: "só sair da poluição e do massacre já é uma boa" (VEJA, 02 de junho de 1976, p. 82).

O montanhismo, também chamado de excursionismo, era encarado em sentido semelhante. Vejamos como Raul Pontual, membro do Centro Excursionista Brasileiro, se posiciona no boletim interno da entidade:

Benditas atividades excursionistas que permitem ao homem de hoje, asfixiado pela vida sedentária e sujeito às poluições da cidade, voltar ao seio purificante da natureza [...] No alto da montanha, o contato com a natureza é o melhor bálsamo para as tensões da vida moderna $(1971$, p. 15$){ }^{4}$

Enfim, como bem sintetiza a matéria publicada na revista Veja de 10 de janeiro de 1975, p. 10:

A idéia de lazer, como costuma ser formulada nos dias de hoje, sugere a necessidade de fuga do trabalho, algo terrível que esmigalha o homem [...] Parece que um fim de semana no campo ou na praia, melhor ainda, doces férias, são remédios adequados para quem gastou energias na repetição de ações absolutamente monótonas em escritórios e fábricas.

O afã pela busca da natureza não se resumirá a sua procura fora da cidade, nos fins de semana. Crescem as iniciativas de trazê-la para dentro das residências. Surge "a mania do verde", no sentido explicitado pela Veja de 18 de agosto de 1976, p. 75: "vasos de

\footnotetext{
${ }^{4}$ Para mais informações sobre o surfe e o montanhismo naquele momento histórico, ver estudo de Dias (2008).

Movimento, Porto Alegre, v. 15, n. 03, p. 249-271, julho/setembro de 2009.
} 
plantas em suas casas e apartamentos ajudam a enfrentar o cenário do concreto da cidade".

Se a nova configuração da cidade se mostrou capaz de influenciar os costumes de lazer, o inverso também se observa: as expectativas e as representações a respeito do uso do tempo livre influenciaram os seus rumos. A disponibilidade de espaços adequados para a recreação passou paulatinamente a ser vista como um problema metropolitano e o crescimento da malha urbana, de alguma forma, teve que considerar os novos desejos de diversão e de contato com a natureza.

Os condomínios da classe média passam a contemplar em seus projetos a existência de espaços livres de lazer, parques e jardins, benefícios que passam a se constituir em forte elemento de valorização do empreendimento, algo bem perceptível até os dias de hoje.

No Rio de Janeiro, com o esgotamento do parque imobiliário da Zona Sul (a área de maior prestigio da cidade), a direção da expansão urbana voltou-se para as "desertas praias da Zona Oeste", a Barra da Tijuca, e por lá se instalam pioneiramente os "novos modos de morar”, em condomínios como Nova Ipanema e Novo Leblon.

Em São Paulo, o bairro Chácara Flora era apresentado como "um pequeno paraíso dentro da capital - ou melhor, encravado numa região a 20 minutos da Praça da Sé [...] A região oferece inúmeras facilidades e opções de lazer e entretenimento para seus moradores" (PONCIANO, 2001, p. 45). A Granja Viana, do mesmo modo, era assim descrita: "um bairro com residências de elevado padrão, escolas e centros comerciais [...] oferecendo o verde e a tranqüilidade dos três mil alqueires da reserva do Horto Florestal" (REVISTA DA ADEMI apud LEITÃO, 1999, p. 85).

Recife também foi se expandindo, sempre buscando as amenidades da vida à beira-mar e do contato com a natureza (VEJA, 17 de fevereiro de 1976). Em 1975, o arquiteto Válter Gordilho teceu comentários sobre fenômeno análogo observado em Salvador:

[...] as classes favorecidas saem em busca de novos ambientes naturais, onde a presença de vegetação e melhores condições ambientais favorecem a escolha

Movimento, Porto Alegre, v. 15, n. 03, p. 249-271, julho/setembro de 2009. 


\title{
262 Artifor Originais
}

de novas opções. Daí o surgimento de loteamentos como o Horto Florestal, Jardim das Bolandeiras e Caminho das Árvores (REVISTA DAADEMI apud LEITÃO, 1999, p. 85).

Tratava-se, portanto, de uma dinâmica que se desenrolava em nível nacional:

\begin{abstract}
Hoje, nas principais cidades brasileiras, nada é mais anunciado nas páginas de imóveis do que loteamentos situados a quilômetros do centro da cidade, onde o homem urbano brasileiro poderá descobrir antiqüíssimas novidades, como o sol ("o pôr do sol, lembra-se?", diz um anúncio de uma imobiliária paulista) (VEJA, 28 de agosto de 1974, p. 52).
\end{abstract}

Enfim, nas décadas de 1950-1970, o crescimento das cidades brasileiras desencadeou uma nova sensibilidade diante da natureza que, por sua vez, também foi acompanhada por outras maneiras de gozar o tempo livre; ambas, da mesma forma, influenciaram nos rumos da nova cidade.

Isto não significa, em absoluto, que tais tendências não existissem antes. Sabemos bem que a gênese dessa dinâmica pode ser identificada já em meados do século XVIII, com a sedimentação de um "pensamento iluminado" e a difusão de uma ética romântica. O "pânico de não fazer nada" e a valorização da natureza como artefato cênico e paisagístico sempre estiveram articulados com o processo moderno de urbanização e com a criação de símbolos da própria modernidade.

No Brasil, ocorrências semelhantes podem ser identificadas ainda mais claramente na transição do século XIX para o XX. No Rio de Janeiro daquele momento, por exemplo, vemos articuladas uma nova conformação do campo esportivo nacional (que trouxe em seu interior uma pioneira possibilidade de celebração das atividades físicas e de culto ao corpo) com as reformas urbanas implementadas sob a liderança de Pereira Passos. Já era perceptível a valorização do mar e da praia como locais de vivências sociais, bem como, deve-se destacar, a construção de passeios públicos e estímulo a novas práticas de lazer (MELO, 2001).

Movimento, Porto Alegre, v. 15, n. 03, p. 249-271, julho/setembro de 2009. 
A questão é que, pelos motivos que procurei demonstrar, na segunda metade do século XX, esse processo parece se intensificar.

\title{
4 LAZER E URBANIZAÇÃO: PREOCUPAÇÕES GOVERNAMENTAIS
}

Nesse contexto, desencadearam-se medidas governamentais no sentido de intervir na organização das cidades. Entre essas iniciativas, destacam-se aquelas que buscavam a valorização das áreas verdes, quase sempre também dedicadas a finalidades de lazer. Esses novos espaços, além disso, estavam ligados às preocupações com a beleza do espaço urbano. Os órgãos públicos tinham que lidar com o fato de que:

\begin{abstract}
A cidade grande está empurrando os brasileiros para fora de casa - para correr, andar de bicicleta, fazer ginástica [...] Em cinco anos, parques, praias, jardins e avenidas das grandes cidades brasileiras foram tomadas por uma legião de atletas de todas as idades, cada vez mais numerosas, cada vez menos inibidas (VEJA, 3 de outubro de 1979, p. 51).
\end{abstract}

Por vários Estados, muitas são as iniciativas implementadas. Vejamos alguns exemplos. No Rio de Janeiro, em 1961, criara-se, com o duplo objetivo de disponibilizar e preservar espaços de natureza, o Parque Nacional da Tijuca. No mesmo sentido, em 1965, é informalmente inaugurada, sob o nome de Parque do Flamengo, uma vasta zona arborizada e equipada para atividades de diversão (OLIVEIRA, 1995).

Nessa mesma cidade, no fim da década de 1960, elaborou-se, o "Plano de Urbanização para a Barra da Tijuca e Baixada de Jacarepaguá", assinado pelo mestre modernista Lúcio Costa, claramente expressando a tendência de valorização do meio ambiente natural: "O plano piloto da Barra da Tijuca emociona na transpiração do amor do artista pela natureza, a ser recriada como argila nas mãos divinas do homem chamado Lúcio Costa". (PLANO, 1969, p. 3). Nas palavras do próprio idealizador do plano: "Esse jogo de trazer o bucólico para dentro da cidade é que é fundamental" (O RIO, 1969, p. 11).

Movimento, Porto Alegre, v. 15, n. 03, p. 249-271, julho/setembro de 2009. 


\section{Artigor Orifinais Cléber Gonçalves, Victor de Melo}

Em São Paulo, já em 1954, inaugurara-se uma grande área verde destinada ao lazer dos paulistanos: o Parque do Ibirapuera. Em 1969, a prefeitura espalhou cartazes estampando flores e convites para práticas de lazer; a ideia era suavizar a paisagem da metrópole. Em 1974, a prefeitura desenvolveu ainda o projeto "Vamos fazer de São Paulo uma cidade agradável", que previa o plantio de 21.000 árvores (VEJA, 01 de julho de 1974).

Em Minas Gerais, no início dos anos 1970, Gil César, Diretor da Superintendência da Capital do Governo Estadual (SUDECAP), preocupado com o problema da recreação das massas, anunciou um projeto que previa a construção de uma praia artificial às margens da lagoa da Pampulha (VEJA, 14 de outubro de 1971). Em 1974, o Departamento de Parques e Jardins teve a iniciativa de plantar mais de 400.000 mudas de árvores por toda a cidade. Encomenda ainda, a Burle Marx, projetos de três grandes praças (VEJA, 26 de junho de 1974).

Em 1975, a prefeitura de Salvador, seguindo o exemplo de Curitiba, que, a essa altura, já era reconhecida como "a cidade modelo" (inclusive por destinar à população grandes área verdes), lançava o projeto "Ampliando o espaço para o homem", criando ruas para pedestres. Em 1977, dentro das iniciativas do projeto "Porto Alegre Urgente", o mesmo ocorre na capital gaúcha: são implementados cerca de 200.000 metros quadrados de ruas de pedestre, com o objetivo de "humanizar a cidade" (VEJA, 11 de junho de 1977).

Já no âmbito do governo federal, em 1973, o II Plano Nacional de Desenvolvimento dedicava grande atenção à questão do planejamento urbano. Em decorrência de suas proposições, criaram-se secretarias, comissões e órgãos especializados para cuidar do "assunto das cidades" em nove áreas metropolitanas: Belém, Belo Horizonte, Curitiba, Fortaleza, Porto Alegre, Recife, Rio de Janeiro, Salvador e São Paulo.

Dando sequência a tal ação, em junho de 1973, realizou-se, no Rio de Janeiro, o "I Encontro das Regiões Metropolitanas" (VEJA, 20 de junho de 1973). Em junho de 1974, criava-se a "Comissão Nacio-nal de Regiões Metropolitanas e Política Urbana”, dotada de

Movimento, Porto Alegre, v. 15, n. 03, p. 249-271, julho/setembro de 2009. 
um orçamento de 240 milhões de cruzeiros, com o objetivo de "tornar possível a vida nas cidades" (VEJA, 12 de junho de 1974, p. 69). No mesmo ano, realizou-se, dessa vez em São Paulo, o "Simpósio Nacional de Política Urbana” (VEJA, 20 de novembro de 1974, p. 58).

Iniciativas no âmbito das políticas de saúde pública são encaminhadas, expressando as preocupações com as "doenças do desenvolvimento". Em agosto de 1978, a Universidade de São Paulo realizou o "Seminário sobre a situação da saúde pública nas áreas metropolitanas", com o objetivo de elaborar diagnósticos dos conglomerados urbanos. Nessa ocasião, em que se discutiram os efeitos da poluição e da violência, o trânsito e a depressão começavam a ser tratados como uma epidemia.

Nos anos 1970, tornaram-se ainda mais frequentes a organização de atividades como passeios ciclísticos e o fechamento de logradouros ao trânsito nos fins de semana, as chamadas ruas de lazer. Seguindo a campanha "Mexa-se", o governo federal lança o programa "Esporte para Todos". Parte da imprensa tratava tais iniciativas como "provas de amor ao lazer", destacando que os indivíduos "continuam receptivos às crescentes iniciativas oficiais na área" (VEJA, 05 de outubro de 1977, p. 72).

O lazer emerge como importante instrumento de "re-humanização", encontrando seu lugar na pauta das agendas públicas. O "Seminário Nacional sobre Lazer", realizado em Curitiba, em novembro de 1974, foi apontado como a iniciativa responsável por ter transportado o "problema da qualidade de vida numa grande cidade para a esfera concreta das preocupações oficiais" (VEJA, 04 de dezembro de 1974, p. 54). Com a presença de arquitetos, urbanistas, sociólogos, economistas e assistentes sociais, o evento foi avaliado como uma "cruzada em favor de uma nova, mais humana e mais atraente fisionomia para as grandes metrópoles contra um universo de tédio, frustrações culturais e desespero que perseguem seus habitantes" (VEJA, 04 de dezembro de 1974, p. 54).

Em 1975, novo congresso seria realizado, dessa vez, no Rio de Janeiro: o I Encontro sobre Lazer, Cultura, Recreação, Educação Física. Começam a ser traduzidos os livros do pesquisador francês

Movimento, Porto Alegre, v. 15, n. 03, p. 249-271, julho/setembro de 2009. 
Joffre Dumazedier, uma importante influência nos primeiros momentos mais sistematizados dos estudos do lazer no país. Nos anos 1970, é ainda publicado outro importante livro: "Lazer no planejamento urbano", de Ethel Bauzer Medeiros. Em breve, a temática passaria também a ser discutida nas universidades e seria tratada como questão acadêmica; as suas relações com a questão urbana não mais abandonariam as pautas de investigação.

O conjunto de preocupações governamentais também cresce no decorrer do século XX, momento em que se estruturam as primeiras secretarias especificamente dedicadas à questão do lazer. Não vou aprofundar tal discussão, na medida em que esse tema e o recorte temporal fogem aos intuitos deste estudo.

\section{CONSIDERAÇões FINAIS}

Robert Park (1973, p. 26) já disse que “[...] a cidade não é apenas uma unidade geográfica”. É algo mais do que uma soma de ruas, edifícios e linhas de trem. É mais do que um amontoado de indivíduos e de conveniências sociais. É mais do que uma mera constelação de instituições e dispositivos administrativos. A cidade é também um estado de espírito, um corpo de costumes, de sentimentos e de atitudes. Assim, " $[\ldots]$ pensar a cidade significa pensar junto a malha urbana e territorial, enfocando-a ainda como um observatório das relações entre os homens" (LEPETIT, 2001, p. 15).

Dessa forma, a estruturação dos espaços das cidades deve ser também entendida à luz dos diversos mecanismos sociais que atuaram na construção e assimilação de novos costumes. A maneira como o processo de urbanização é conduzido tem forte relação com as formas e os estilos de vida da população. Ambas as dimensões respondem a uma mesma condição de possibilidade, onde tanto os hábitos culturais quanto à forma física da cidade estão se interinfluenciando, dramatizando e materializando o conjunto de mudanças. Como lembra Gilberto Velho (1995, p. 228):

Movimento, Porto Alegre, v. 15, n. 03, p. 249-271, julho/setembro de 2009. 
Paralelamente a uma reorganização do espaço, às transformações na economia e na vida política contemporânea, a sua constituição e natureza estão indissociavelmente associadas a modos específicos de recortar e construir a realidade. Ela é conseqüência e, simultaneamente, causa de novas visões de mundo com concepções particulares de tempo, espaço e indivíduo.

Essas interfaces evidenciam como a estruturação das cidades é capaz de influenciar, em alguma medida, a expectativa da população com relação ao usufruto do seu tempo de não trabalho. Da mesma forma, também é possível observar como os novos desejos e expectativas de aproveitamento do tempo livre são capazes de contribuir para o consolidar de um complexo sistema de representações que, pouco a pouco, vai exigindo a edificação de novos espaços, a materialização de uma nova cidade, capaz de dar conta das demandas colocadas por esses novos hábitos.

Sob esta perspectiva, o estudo das relações entre espaço e cultura pode ampliar, inclusive heuristicamente, a inteligibilidade tanto do fenômeno urbano quanto do fenômeno lazer. Para pensar a cidade em sua complexidade, tem-se de olhar, simultaneamente, para o lugar e para as pessoas, o espaço e seus atores.

É nesse sentido que parece alvissareiro um aprofundamento do estudo das relações entre o processo de urbanização e a formação de certos hábitos de lazer. Para além das planificações e outras projeções políticas, a configuração de uma cidade também é constituída pelos usos cotidianos a que cada uma das suas estruturas estará submetida. E certamente, como procuro discutir, as maneiras que os homens e as mulheres que ocupam esses espaços utilizam para usufruir de seu tempo livre é um importante elemento para permitir produzir alterações e reapropriações desse complexo a que se chama de cidade.

Movimento, Porto Alegre, v. 15, n. 03, p. 249-271, julho/setembro de 2009. 


\title{
268 Artigos Origimais Cléber Gonçalves, Victor de Melo
}

\begin{abstract}
Leisure and urbanization in Brazil: notes of a recent history (1950's/1970's)

Abstract: This article has for purpose to argue the relation between the increase of the urbanization process in Brazil and the new arrangements of the leisure in our society. The aim is to analyze the possible correspondences between a certain aspect of the culture (leisure) and the forms assumed or idealized for a territory. For reach our objective, beyond a revision of literature, we use as source a magazine of great circulation, penetration and influence, launched in 1960's: Veja.

Keywords: Leisure activities. Urbanization. Nature. Cities.
\end{abstract}

Ocio y urbanización en Brasil: notas de una historia reciente (décadas de 1950/1970)

Resumen: Ese artículo intenta discutir la relación entre la aceleración del proceso de urbanización en Brasil, observable desde los años 1950 y aún más intensamente durante los años 1960 y 1970, y los nuevos arreglos del fenómeno ocio en nuestra sociedad. El objetivo es examinar las posibles conexiones entre un aspecto de la cultura (el ocio/entretenimiento) y las formas asumidas o idealizadas para un territorio. Para alcanzar nuestro objetivo, hicimos inicialmente una revisión de la literatura y posteriormente utilizamos como fuente principal un periódico semanal principal de gran circulación, lanzado en los años 1960: la revista Veja. Palabras clave: Actividades recreativas. Urbanización. Naturaleza. Ciudades.

\section{REFERÊNCIAS}

ABREU, M. de S. A evolução urbana do Rio de Janeiro. Rio de Janeiro: IPP, 2006.

ALMEIDA, M. H. T. de; WEIS, L. Carro-zero e pau-de-arara: o cotidiano da oposição de classe média ao regime militar. In: SCHWARCZ, L.M. (org.). História da vida privada no Brasil: contrastes da intimidade contemporânea. São Paulo: Companhia das Letras, v. 4, 1988.

CANCLINI, N. G. Consumidores e cidadãos. Rio de Janeiro: Editora da UFRJ, 1995.

CENTRO DE ESTUDOS DA METRÓPOLE. O uso do tempo livre e as práticas culturais na região metropolitana de São Paulo: relatório da primeira etapa da pesquisa. São Paulo: Cebrap, 2005.

Movimento, Porto Alegre, v. 15, n. 03, p. 249-271, julho/setembro de 2009. 
CORBIN, A. História dos tempos livres. Lisboa: Teorema, 2001.

CUNHA, R. V. França: crise e esperança. Jornal do Brasil, Rio de Janeiro, Caderno especial: A guerra de nossos dias, 01 de setembro de 1968.

DIAS, C. A. Urbanidades da natureza: o montanhismo, o surfe e as novas configurações do esporte no Rio de Janeiro. Rio de Janeiro: Apicuri, 2008.

FURTADO, C. O Brasil pós-milagre. 8. ed. Rio de Janeiro: Paz e Terra, 1983.

HOBSBAWM, E. Era dos extremos: o breve século XX - 1914-1991. São Paulo: Companhia das Letras, 1988

LEITÃO, G. A construção do eldorado urbano: o plano piloto da Barra da Tijuca e Baixada de Jacarepaguá - 1970/1988. Niterói: EdUFF, 1999.

LEPETIT, B. Por uma nova história urbana. São Paulo: Edusp, 2001.

LESSA, C. O Rio de todos os Brasis. 3. ed. Rio de Janeiro: Record, 2000.

MELLO, J. M. C. de; NOVAIS, F. A. Capitalismo tardio e sociabilidade moderna. In: SCHWARCZ, L.M. (org.). História da vida privada no Brasil: contrastes da intimidade contemporânea. São Paulo: Companhia das Letras, v. 4, 1998.

MELO, V. A. de. Cidade Sportiva: primórdios do esporte no Rio de Janeiro. Rio de Janeiro: Relume Dumará, 2001.

MELO, V.; PERES, F. Lazer, esporte e cultura urbana na transição dos séculos XIX e XX: conexões entre Paris e Rio de Janeiro. Logos, Rio de Janeiro, v. 12, n.22, 2005.

MOREIRA, V. M. L. Os anos JK: industrialização e modelo oligárquico de desenvolvimento rural. In: FERREIRA, J., DELGADO, L. de A.N. (org.). O Brasil Republicano. Rio de Janeiro: Civilização Brasileira, v. 3, 2003.

O CRUZEIRO. O Rio caminha para a Barra. Rio de Janeiro, 25 de setembro de 1969.

O GLOBO. Plano da Barra restitui ao Rio sua unidade. Rio de Janeiro, p. 12, 25 de abril de 1969.

OLIVEIRA, C. Flores raras e banalíssimas. Rio de Janeiro, Rocco, 1995.

PARK, R. A cidade: sugestões para a investigação do comportamento humano no meio urbano. In: VELHO, O.G. (Org.). O fenômeno urbano. 2. ed. Rio de Janeiro, Zahar, 1973.

PONCIANO, L. Bairros Paulistanos de A a Z. São Paulo, SENAC, 2001.

PONTUAL, R. A tensão nervosa dos nossos tempos. Boletim informativo do Centro Excursionista Brasileiro, Rio de Janeiro, n. 287, 1971.

Movimento, Porto Alegre, v. 15, n. 03, p. 249-271, julho/setembro de 2009. 


\section{Artifor Originais}

Cléber Gonçalves, Victor de Melo

PRADO, L. C. D.; EARP, F. de S. O milagre brasileiro: crescimento acelerado, integração internacional e concentração de renda (1967 - 1973). In: FERREIRA, J., DELGADO, L. de A. N. (org.). O Brasil Republicano. Rio de Janeiro: Civilização Brasileira, v. 3, 2003.

REZENDE, V. F. Planos e regulação urbanística: a dimensão normativa das intervenções na cidade do Rio de Janeiro. In: OLIVEIRA, L. L. (org.). Cidade: história e desafios. Rio de Janeiro: FGV, 2002.

ROMERO, J. L. América Latina: as cidades e as idéias. Rio de Janeiro: UFRJ, 2004.

SILVA, A. Imaginários urbanos. São Paulo: Perspectiva, 2001.

VEBLEN, T. A teoria da classe ociosa. São Paulo: Nova Cultural, 1987.

VEJA. O turismo sob as lonas. São Paulo: Abril, n. 18, p. 49-50, 08 de janeiro de 1969.

Férias para todos. São Paulo: Abril, n. 67, p. 74, 17 de dezembro de 1969.

Cidades. São Paulo: Abril, p. 58, 14 de outubro de 1971.

Áreas metropolitanas: ainda sem planos. São Paulo: Abril, n. 250, p. 83, 20 de junho de 1973.

Delícias do verão, n. 275, p. 80-88, 12 de dezembro de 1973.

Cidades de venda. São Paulo: Abril, n. 282, p. 40-41, 30 de janeiro de 1974.

Política urbana: chega de desordem. São Paulo: Abril, n. 301, p. 69, 12 de junho de 1974. de 1974.

Belo Horizonte: retorno ao vergel. São Paulo: Abril, n. 303, p. 69, 26 de junho

São Paulo: cuidando da beleza. São Paulo: Abril, n. 305, p. 63-64, 10 de julho de 1974. $\overline{1974 .}$

A explosão das cidades. São Paulo: Abril, n. 312, p. 52-61, 28 de agosto de

Sem evasivas. São Paulo: Abril, n. 324, p. 58, 20 de novembro de 1974.

O lazer como tema. São Paulo: Abril, n. 326, p. 59, 02 de dezembro de 1974.

Mais ginástica. São Paulo: Abril, n. 326, p. 50, 02 de dezembro de 1974.

Carta ao leitor (Editorial). São Paulo: Abril, p. 10-11, 10 de janeiro de 1975.

. Litoral ocupado. São Paulo: Abril, n. 393, p. 49, 17 de março de 1976.

Movimento, Porto Alegre, v. 15, n. 03, p. 249-271, julho/setembro de 2009. 
. Festa de feras. São Paulo: Abril, n. 404, p. 82, 02 de junho de 1976.

Atração do verde. São Paulo: Abril, n. 415, p. 75, 18 de agosto de 1976.

Férias na fazenda. São Paulo: Abril, n. 437, p. 92-94, 19 de janeiro de 1977.

Ofensiva paulista. São Paulo: Abril, n. 458, p. 54, 15 de junho de 1977. $\overline{1977 .}$

Porto Alegre: esquina segura. São Paulo: Abril, n. 458, p. 54, 15 de junho de $\overline{19773}$.

Lazer: o fenômeno. São Paulo: Abril, n. 474, p. 72-7, 05 de outubro de O paraíso. São Paulo: Abril, n. 477, p. 63, 26 de outubro de 1977.

Rápido e barato. São Paulo: Abril, n. 484, p. 50, 14 de dezembro de 1977.

A aventura da fuga. São Paulo: Abril, n. 532, p. 55, 15 de novembro de 1978.

1979

O suor entrou na moda. São Paulo: Abril, n. 578, p. 50-59, 03 de outubro de

VELHO, G. Estilo de vida urbano e modernidade. Estudos Históricos, v. 8, n. 16, 1995.

VIZENTINI, P. G. F. Do nacional-desenvolvimentismo à política externa independente (1945-1964). In: FERREIRA, J., DELGADO, L. de A. N. (org.). O Brasil Republicano. Rio de Janeiro, Civilização Brasileira, v. 3, 2003.

Recebido em: 05.06.2008

Aprovado em: 13.05.2009

Movimento, Porto Alegre, v. 15, n. 03, p. 249-271, julho/setembro de 2009. 